\title{
Aboveground biomass and corresponding carbon sequestration ability of four major forest types in south China
}

\author{
CHEN QingQing ${ }^{1,3}$, XU WeiQiang $^{1,3}$, LI ShengGong $^{2}$, FU ShengLei $^{1} \&$ YAN JunHua ${ }^{1 *}$ \\ ${ }^{1}$ South China Botanical Garden, Chinese Academy of Sciences, Guangzhou 510650, China; \\ ${ }^{2}$ Institute of Geographic Sciences and Natural Resources Research, Chinese Academy of Sciences, Beijing 100101, China; \\ ${ }^{3}$ Graduate University of Chinese Academy of Sciences, Beijing 100049, China
}

Received December 28, 2011; accepted February 7, 2012; published online June 21, 2012

\begin{abstract}
We estimated aboveground biomass carbon $\left(T_{\mathrm{ABC}}\right)$ and net carbon accumulation rates $\left(T_{\mathrm{NEP}}\right)$ for trees in four major forest types based on national forest inventory data collected in 1994-1998 and 1999-2003. The four types were Pinus massoniana forest, Cunninghamia lanceolata forest, hard broad-leaved evergreen forest and soft broad-leaved evergreen forest. We analyzed variations in $T_{\mathrm{ABC}}$ and $T_{\mathrm{NEP}}$ for five stand ages (initiation, young, medium, mature and old). In both time periods, estimated $T_{\mathrm{ABC}}$ in all four forest types increased consistently with forest stand age and the oldest stage had the largest $T_{\mathrm{ABC}}$ compared with other stages. Broad-leaved forests (hard and soft) had higher $T_{\mathrm{ABC}}$ than needle-leaved forests (Pinus massoniana and Cunninghamia lanceolata) for each of the five age stages. The difference of $T_{\mathrm{ABC}}$ between broad-leaved and needle-leaved forests increased with forest stand age. Comparison of estimated $T_{\mathrm{NEP}}$ by age category indicated $T_{\mathrm{NEP}}$ increased from the initiation stage to the young stage, and then decreased from the mature stage to old stage in all four forest types. $T_{\mathrm{NEP}}$ for any particular stage depended on the forest type; for instance, broad-leaved forests at both the mature and old stages had greater $T_{\mathrm{NEP}}$ than in needle-leaved forests. A logistic curve was applied to fit the relationship between $T_{\mathrm{ABC}}$ and forest stand age. In each period, correlations in all four forest types were all statistically significant $(P<0.01)$ with $R^{2}>0.95 . T_{\mathrm{ABC}}$ was therefore predicted by these regression functions from 2000 to 2050 and the mean $T_{\text {NEP }}$ during the predicted period was estimated to be about $41.14,31.53,75.50$ and $75.68 \mathrm{~g} \mathrm{C} \mathrm{m}^{-2} \mathrm{a}^{-1}$ in Pinus massoniana forest, Cunninghamia lanceolata forest, hard broad-leaved forest and soft broad-leaved forest, respectively. Results from both forest inventory and regression prediction suggest broad-leaved forests are greater carbon sinks, and hence have greater carbon sequestration ability especially in the mature and old stages when compared to needle-leaved forests. Broad-leaved forests should have high levels of carbon sequestration when compared with needle-leaved forests in south China.
\end{abstract}

broad-leaved forest, needle-leaved forest, aboveground biomass, carbon accumulation rate, logistic regression

Citation: Chen Q Q, Xu W Q, Li S G, et al. Aboveground biomass and corresponding carbon sequestration ability of four major forest types in south China. Chin Sci Bull, 2013, 58: 1551-1557, doi: 10.1007/s11434-012-5100-8

Globally, forest ecosystems are significant carbon pools because forests absorb carbon dioxide $\left(\mathrm{CO}_{2}\right)$ from the atmosphere through photosynthesis [1]. Tropical and subtropical forests have accounted for more than $40 \%$ of global gross primary production [2] and net carbon uptake over the past two decades [3-5]. Carbon sequestration in tropical and subtropical regions has been receiving increased attention because these forests grow year round and have intense photosynthetic activity and a wide diversity of species $[6,7]$.

*Corresponding author (email: jhyan@scbg.ac.cn)
Biomass directly reflects forest carbon pools, while the net carbon accumulation rate $\left(T_{\mathrm{NEP}}\right)$ determines the potential of carbon sequestration in forest ecosystems [8]. Many previous studies have reported the changes of biomass and $T_{\mathrm{NEP}}$ with forest stand age [9-11]. Few studies have examined the differences of biomass carbon and net carbon sequestration ability related to forest stand age among different forest types, especially in tropical and subtropical forests.

In the present study, aboveground biomass carbon $\left(T_{\mathrm{ABC}}\right)$ and $T_{\mathrm{NEP}}$ for trees in four major forest types were estimated using the national forest inventory data from two periods, 
1994-1998 and 1999-2003. In each period, $T_{\mathrm{ABC}}$ and $T_{\mathrm{NEP}}$ were compared for five age categories: initiation, young, medium, mature and old (Table 1). Also, $T_{\mathrm{ABC}}$ and mean $T_{\mathrm{NEP}}$ were estimated based on the logistic regression function between $T_{\mathrm{ABC}}$ and forest stand age, with $T_{\mathrm{ABC}}$ estimated for each decade from 2000 to 2050. The objectives of this study were (1) to explore the ability of four forest types in five age categories to sequester carbon, and (2) to provide a scientific basis for future policy decisions related to the sustainable management of forests in an environmentfriendly manner in southern China.

\section{Methods}

\subsection{Study site and forest type}

The study site covers most of the tropical and subtropical regions in south China $\left(3^{\circ} 30^{\prime}-30^{\circ} 72^{\prime} \mathrm{N}, 103^{\circ} 36^{\prime}-122^{\circ} 45^{\prime} \mathrm{E}\right)$, including eight provinces (region): Fujian, Guangdong, Guangxi, Guizhou, Hainan, Hunan, Jiangxi and Zhejiang (Figure 1). The total area of land surface is about $1.2 \times 10^{12} \mathrm{~m}^{2}$. Highly diverse evergreen forests dominate the area of broad-leaved and needle-leaved species. The forested area within the study site covers about $4.1 \times 10^{11} \mathrm{~m}^{2}$ with a timber volume of $2.1 \times 10^{9} \mathrm{~m}^{3}$, including $23.4 \%$ and $15.0 \%$ of the total forest area and timber volume in China, respectively [12]. The region has a typical tropical and subtropical monsoon climate with distinct wet and dry seasons. The mean annual precipitation in the eight provinces ranges from 1200 to $1800 \mathrm{~mm}$ and the mean annual temperature varies from 16 to $20^{\circ} \mathrm{C}$. Table 2 summarizes additional details of site characteristics.

Based on the "National Forest Resources Inventory of Continuous Technical Regulations" [13], four forest types,

Table 2 Ecological characteristics of eight provinces in the tropical and subtropical regions of south China

\begin{tabular}{cccccc}
\hline & \multicolumn{5}{c}{ Forest stand age (a) } \\
\cline { 2 - 6 } Forest type & $\begin{array}{c}\text { Initiation } \\
(\mathrm{A})\end{array}$ & $\begin{array}{c}\text { Young } \\
(\mathrm{B})\end{array}$ & $\begin{array}{c}\text { Medium } \\
(\mathrm{C})\end{array}$ & $\begin{array}{c}\text { Mature } \\
(\mathrm{D})\end{array}$ & Old (E) \\
\hline $\begin{array}{c}\text { Masson pine forest } \\
\text { Cunninghamia }\end{array}$ & $<11$ & $11-20$ & $21-30$ & $31-50$ & $>50$ \\
$\begin{array}{c}\text { forest } \\
\text { Hard broad-leaved } \\
\text { forest }\end{array}$ & $<11$ & $11-20$ & $21-25$ & $26-35$ & $>35$ \\
$\begin{array}{c}\text { Soft broad-leaved } \\
\text { forest }\end{array}$ & $<21$ & $41-60$ & $61-80$ & $81-120$ & $>120$ \\
\hline
\end{tabular}

Table 1 Division of the five age stages for the four forest types

\begin{tabular}{|c|c|c|c|c|c|}
\hline Province/region & Latitude(N) & Longitude(E) & $\begin{array}{c}\text { Mean temperature in } \\
\text { winter }\left({ }^{\circ} \mathrm{C}\right)\end{array}$ & $\begin{array}{l}\text { Mean temperature } \\
\text { in summer }\left({ }^{\circ} \mathrm{C}\right)\end{array}$ & $\begin{array}{c}\text { Average annual } \\
\text { precipitation }(\mathrm{mm})\end{array}$ \\
\hline Hainan & $3^{\circ} 30^{\prime}-20^{\circ} 18^{\prime}$ & $108^{\circ} 37^{\prime}-111^{\circ} 05^{\prime}$ & $17-22$ & $26-29$ & $900-2600$ \\
\hline Guangdong & $20^{\circ} 13^{\prime}-25^{\circ} 31^{\prime}$ & $109^{\circ} 39^{\prime}-117^{\circ} 19^{\prime}$ & $9-23$ & $27-29$ & $1500-2000$ \\
\hline Guangxi & $20^{\circ} 54^{\prime}-26^{\circ} 24^{\prime}$ & $104^{\circ} 26^{\prime}-112^{\circ} 04^{\prime}$ & $6-15$ & $23-28$ & $1300-2400$ \\
\hline Fujian & $23^{\circ} 33^{\prime}-28^{\circ} 20^{\prime}$ & $115^{\circ} 50^{\prime}-120^{\circ} 40^{\prime}$ & $7-13$ & $28-30$ & $1200-2200$ \\
\hline Guizhou & $24^{\circ} 30^{\prime}-29^{\circ} 13^{\prime}$ & $103^{\circ} 31^{\prime}-109^{\circ} 30^{\prime}$ & $4-9$ & $20-28$ & $900-1500$ \\
\hline Jiangxi & $24^{\circ} 07^{\prime}-29^{\circ} 09^{\prime}$ & $114^{\circ} 02^{\prime}-118^{\circ} 28^{\prime}$ & $4-9$ & $28-30$ & $1300-1800$ \\
\hline Zhejiang & $27^{\circ} 08^{\prime}-30^{\circ} 27^{\prime}$ & $118^{\circ} 05^{\prime}-122^{\circ} 45^{\prime}$ & $3-7$ & $28-30$ & $1200-1800$ \\
\hline
\end{tabular}

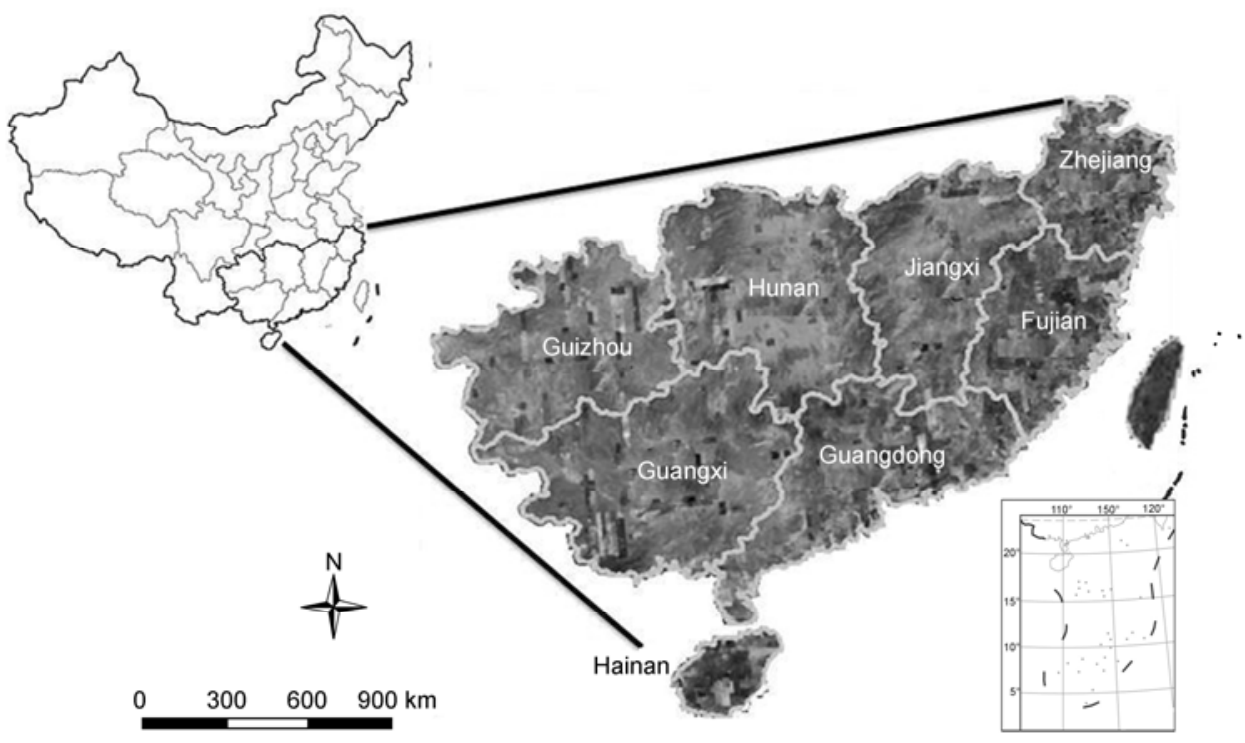

Figure 1 Location of the study site. 
containing 10 tree species, were chosen for the present study. They could be divided into the two groups, needle-leaved and broad-leaved forests. Needle-leaved forests include both Masson pine (Pinus massoniana) and Cunninghamia (Cunninghamia lanceolata). Broad-leaved forests include two types, hard broad-leaved forest (oak, Cinnamomum camphora, Phoebe zhennan and hard broadleaved mixed species) and soft broad-leaved forest (Betulaceae, Tiliaceae, Scrophulariaceae and soft broad-leaved mixed species). These four forest types occupied $87.7 \%$ of the area and contained $89.0 \%$ of the timber volume of the entire study site. Basically, they were representatives of all forest types in the tropical and subtropical regions of south China [12]. Using the forest stand age division standards of the Chinese forest inventory [13], all four forest types were classified into these five age categories: initiation (A), young (B), medium (C), mature (D) and old (E). Table 1 provides a breakdown of the stand age classifications.

\subsection{Calculation of aboveground biomass carbon $\left(T_{\mathrm{ABC}}\right)$}

The national forest resources inventory has been conducted every five years to review changes in forest area and timber volume including stand age and forest type (species) in each province. This study used inventory data from two periods, 1994-1998 and 1999-2003, to calculate $T_{\mathrm{ABC}}\left(\mathrm{g} \mathrm{C} \mathrm{m}^{-2}\right)$ of the tree layer as follows:

$$
T_{\mathrm{ABC}}=\frac{\sum_{i=1}^{n} \sum_{j=1}^{m} B_{i, j} \times S_{i, j}}{\sum_{i=1}^{n} S_{i}},
$$

where $n$ and $m$ represent forest type and tree species, respectively. $S_{i}$ is the area $\left(\mathrm{m}^{2}\right)$ of the $i$ th forest type, $S_{i j}$ is the area of the $j$ th tree species in the $i$ th forest type, $B_{i j}$ is the aboveground carbon biomass $\left(\mathrm{g} \mathrm{C} \mathrm{m}^{-2}\right)$ of the $j$ th tree species in the $i$ th forest type. $B_{j}$ can be estimated as follows:

$$
B_{j}=0.5 \times \frac{\delta_{j} \times V_{j}}{S_{j}},
$$

where 0.5 is the convention coefficient of carbon to biomass, $V_{j}$ is the timber volume $\left(\mathrm{m}^{3}\right)$ of the $j$ th tree species, $S_{j}$ is the area $\left(\mathrm{m}^{2}\right)$ of the $j$ th tree species. $\delta_{j}$ is the specific biomass expansion factor $\left(\mathrm{g} \mathrm{m}^{-3}\right)$ of the $j$ th tree species, which can be estimated as follows:

$$
\delta_{j}=C_{1}+\frac{C_{2}}{V_{j}},
$$

where $C_{1}\left(\mathrm{~g} \mathrm{~m}^{-3}\right)$ and $C_{2}(\mathrm{~g})$ are estimated parameters for specific tree species, more extensive description of the methods to estimate $C_{1}$ and $C_{2}$ were shown in a previous study [14]. If there were no estimated $C_{1}$ and $C_{2}$ for some species in the present study, parameters derived from a similar species in the same region were used. We used eqs. (1) - (3) to calculate $T_{\mathrm{ABC}}$ for all five forest stand age stages. A logistic regression curve was applied to fit the relationship between $T_{\mathrm{ABC}}$ and forest stand age. In each period, correlations in all four forest types were all statistically significant $(P<0.01)$ with $R^{2}>0.95$ (Figure 2 ).

\subsection{Calculation and prediction of the carbon accumu- lation rate $\left(\boldsymbol{T}_{\mathrm{NEP}}\right)$}

$T_{\mathrm{NEP}}$ was estimated as follows

$$
T_{\mathrm{NEP}}=\frac{T_{\mathrm{ABC}}^{\prime}-T_{\mathrm{ABC}}^{0}}{t^{\prime}-t^{0}},
$$

where $t$ is the time (year), and $T_{\mathrm{ABC}}^{0}$ and $T_{\mathrm{ABC}}^{\prime}$ are the values of aboveground biomass carbon $\left(\mathrm{g} \mathrm{C} \mathrm{m}^{-2}\right)$ at $t^{0}$ and $t^{\prime}$ time, respectively. Using the logistic curve derived from forest inventory data, $T_{\mathrm{ABC}}$ was predicted until 2050 and $T_{\mathrm{NEP}}$ was estimated at intervals of 5 years for the initiation, young and medium stages and at intervals of 10 years for the mature and old stages.

\subsection{Data analysis}

The effects of stand age on the variations of $T_{\mathrm{ABC}}$ and $T_{\mathrm{NEP}}$ were examined by performing one-way analysis of variance, and multiple comparisons using the ANOVA procedure of SAS (Version 8.0; SAS Institute Inc., 1999). The logistic regression curves (variation of $T_{\mathrm{ABC}}$ with forest stand age) were plotted using the built-in statistical program Origin (Version 8.0; Origin Lab, 2007).

\section{Results}

\subsection{Changes in $T_{\mathrm{ABC}}$}

Figure 3 shows the estimated $T_{\mathrm{ABC}}$ increased continuously with forest stand age across all four forest types in the two time periods, 1994-1998 and 1999-2003, respectively. Previous studies had reported $T_{\mathrm{ABC}}$ maintained a balance or slight decline in mature and old forest stages [15-17], but this study found a significant increase of $T_{\mathrm{ABC}}$ between mature and old stages (Figure 3 ). The differences of $T_{\mathrm{ABC}}$ among all age stages were significant $(P<0.01)$ for the four forest types (Figure 3).

From the initiation stage to the old stage, $T_{\mathrm{ABC}}$ increased from $484.6 \mathrm{~g} \mathrm{C} \mathrm{m}^{-2}$ to $3030.4 \mathrm{~g} \mathrm{C} \mathrm{m}^{-2}$ and from 431.5 to $2224.7 \mathrm{~g} \mathrm{C} \mathrm{m}^{-2}$ for Masson pine forest and Cunninghamia forest, respectively in the period of 1994-1998. For the two broad-leaved forest types, $T_{\mathrm{ABC}}$ increased from 1343.9 to $10626.5 \mathrm{~g} \mathrm{C} \mathrm{m}^{-2}$ and from 1816.1 to $6910.3 \mathrm{~g} \mathrm{C} \mathrm{m}^{-2}$ for hard broad-leaved forest and soft broad-leaved forest, respectively. Similar results were found for the period of 1999-2003. Accordingly, there was no significant difference in $T_{\mathrm{ABC}}$ between the two periods for the same forest type $\left(P_{\text {Masson pine }}=0.96, P_{\text {Cunninghamia }}=0.75, P_{\text {hard boardleaf }}=\right.$ $\left.0.92, P_{\text {soft boardleaf }}=0.86\right)($ Figure 3$)$.

$T_{\mathrm{ABC}}$ in broad-leaved forests was much greater than $T_{\mathrm{ABC}}$ 


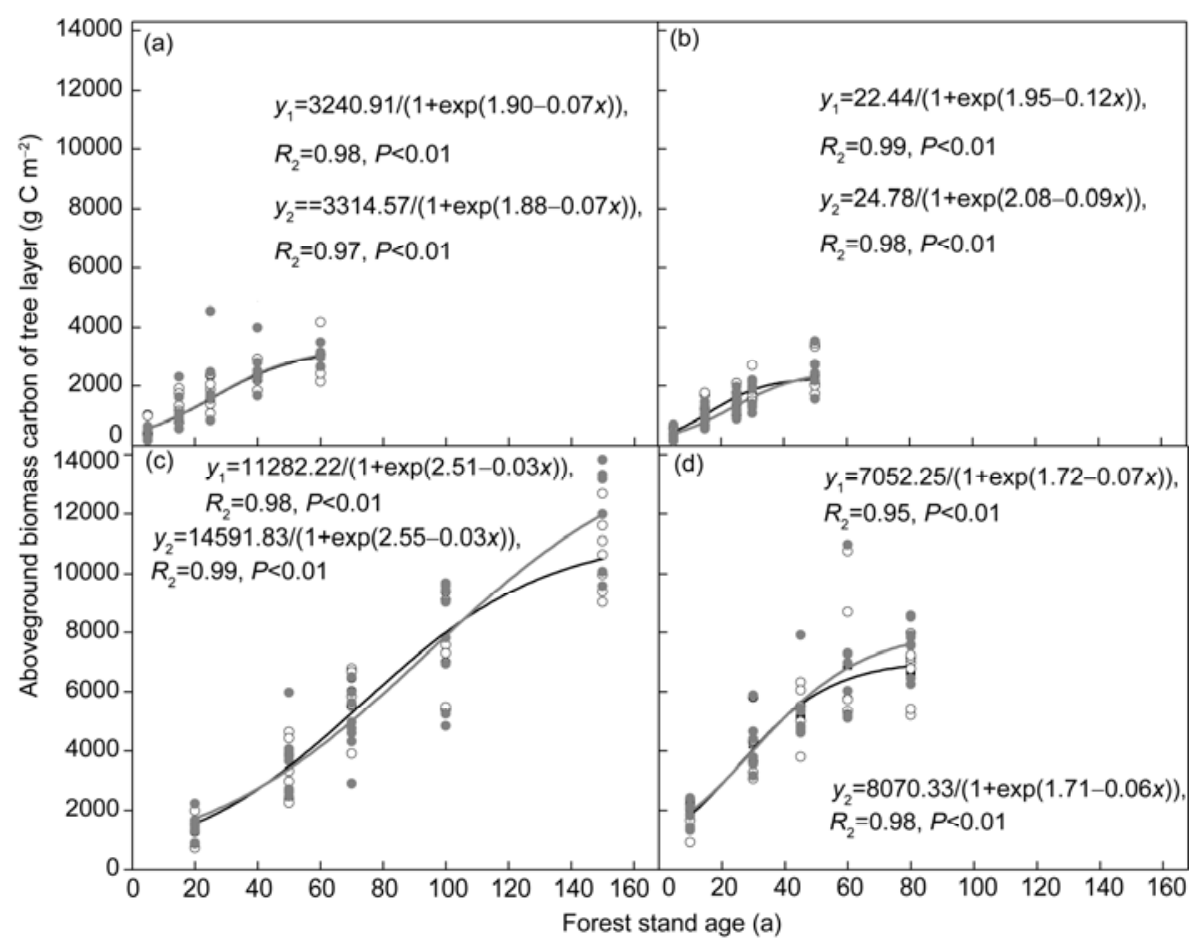

Figure 2 Logistic regression curves for the variations of aboveground biomass carbon $\left(T_{\mathrm{ABC}}, \mathrm{g} \mathrm{C} \mathrm{m}^{-2}\right)$ of the tree layer with forest stand age in the four forest types: Masson pine forest (a), Cunninghamia forest (b), hard broad-leaved forest (c) and soft broad-leaved forest (d). Empty dots ( $(\circ)$ and filled dots $(\bullet)$ represent $T_{\mathrm{ABC}}$ of the eight provinces in the two periods of 1994-1998 and 1999-2003, respectively. $y_{1}$ and $y_{2}$ are logistic regression equations for the two periods of 1994-1998 and 1999-2003, respectively.

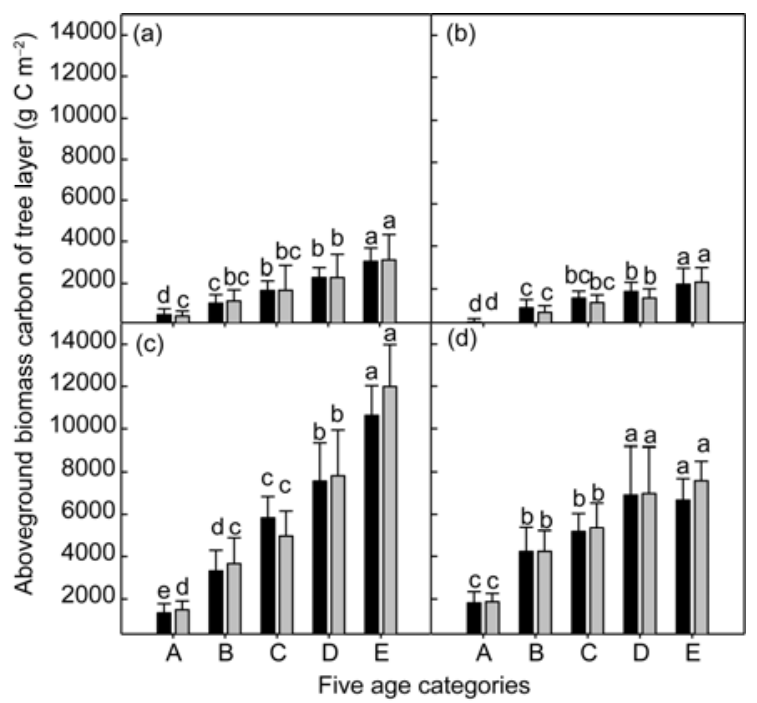

Figure 3 Aboveground carbon biomass in the tree layer $\left(T_{\mathrm{ABC}}, \mathrm{g} \mathrm{C} \mathrm{m}^{-2}\right)$ for the five age categories (initiation (A), young (B), medium (C), mature (D) and old (E)) in the four forest types: Masson pine forest (a), Cunninghamia forest (b), hard broad-leaved forest (c) and soft broad-leaved forest (d). Mean and standard deviation of the estimated $T_{\mathrm{ABC}}$ were calculated for the years 1994-1998 (grey bars) and 1999-2003 (dark bars) based on data from the eight provinces (region). For clarity, only the upper error bars for the four plots are shown.

in needle-leaved forests. Figure 3 also shows these differences increased with forest stand age. For the four forest types, the mean $T_{\mathrm{ABC}}$ was the largest in hard broad-leaved forest and the least in Cunninghamia forest. The differences of $T_{\mathrm{ABC}}$ among the four forest types were significant in both time periods, $1994-1998\left(P_{1994-1998}=0.03\right)$ and $1999-2003$ $\left(P_{1999-2003}=0.01\right)$.

\subsection{Changes in $T_{\mathrm{NEP}}$}

Figure 4 shows the estimated $T_{\mathrm{NEP}}$ for each age stage and forest type. $T_{\mathrm{NEP}}$ in both periods (1994-1998 and 19992003) increased from the initiation stage to the young stage, and then decreased from the mature stage to the old stage in the four forest types. Figure 4 shows $T_{\text {NEP }}$ was the largest in the young stage in all forest types except for hard broad-leaved forest. The differences of $T_{\mathrm{NEP}}$ among all age stages were significant $(P<0.01)$ for all four forest types (Table 3).

In the period of 1994-1998, $T_{\mathrm{NEP}}$ were 3.6-63.4, 10.7-61.8, 31.3-109.6, 36.0-125.1 $\mathrm{g} \mathrm{C} \mathrm{m}^{-2} \mathrm{a}^{-1}$ for all five age stages for Masson pine forest, Cunninghamia forest, hard broad-leaved forest, and soft broad-leaved forest, respectively. For 1999-2003, a slightly greater $T_{\mathrm{NEP}}$ in all four forest types was found compared with data from 1994-1998. This probably reflected global changes such as rising atmospheric $\mathrm{CO}_{2}$, warming, nitrogen deposition and so on $[18,19]$.

The mean $T_{\mathrm{NEP}}$ in broad-leaved forests was much greater $\left(81.4 \mathrm{~g} \mathrm{C} \mathrm{m}^{-2} \mathrm{a}^{-1}\right)$ than mean $T_{\mathrm{NEP}}$ in needle-leaved forests $\left(41.8 \mathrm{~g} \mathrm{C} \mathrm{m}^{-2} \mathrm{a}^{-1}\right)$. For the four forest types, the mean $T_{\mathrm{NEP}}$ was the largest in soft broad-leaved forest $\left(90.4 \mathrm{~g} \mathrm{C} \mathrm{m}^{-2} \mathrm{a}^{-1}\right)$ 
Table 3 Statistical multiple comparison of $T_{\mathrm{NEP}}$ across the five age categories (initiation (A), young (B), medium (C), mature (D) and old (E)) for the four forest types

\begin{tabular}{|c|c|c|c|c|c|c|c|c|}
\hline \multirow{2}{*}{ Age category } & \multicolumn{2}{|c|}{ Masson pine forest } & \multicolumn{2}{|c|}{ Cunninghamia forest } & \multicolumn{2}{|c|}{ Hard broad-leaved forest } & \multicolumn{2}{|c|}{ Soft broad-leaved forest } \\
\hline & 1994-1998 & $1999-2003$ & $1994-1998$ & 1999-2003 & $1994-1998$ & $1999-2003$ & $1994-1998$ & $1999-2003$ \\
\hline A & a & $a b$ & $a b$ & $\mathrm{ab}$ & $\mathrm{b}$ & $\mathrm{b}$ & a & a \\
\hline $\mathrm{B}$ & $\mathrm{a}$ & a & a & a & $\mathrm{a}$ & $\mathrm{a}$ & $\mathrm{a}$ & $\mathrm{a}$ \\
\hline $\mathrm{C}$ & a & $a b$ & $a b$ & a & $\mathrm{a}$ & a & $a b$ & $a b$ \\
\hline $\mathrm{D}$ & $\mathrm{b}$ & b & b & $\mathrm{b}$ & b & $\mathrm{a}$ & $\mathrm{bc}$ & bc \\
\hline $\mathrm{E}$ & $\mathrm{c}$ & $\mathrm{c}$ & c & c & c & $\mathrm{b}$ & $\mathrm{c}$ & c \\
\hline
\end{tabular}

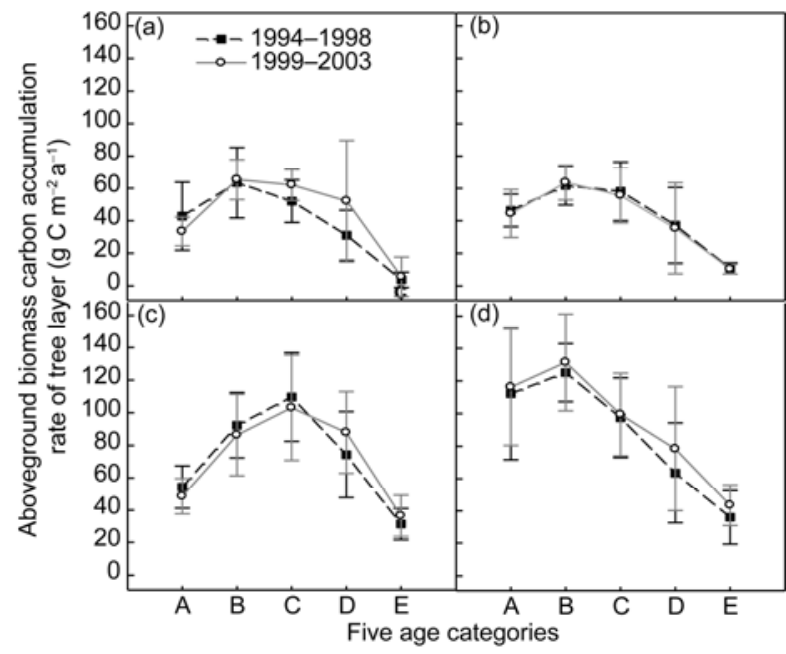

Figure 4 Aboveground biomass carbon accumulation rates in the tree layer $\left(T_{\mathrm{NEP}}, \mathrm{g} \mathrm{C} \mathrm{m}^{-2} \mathrm{a}^{-1}\right)$ for the five age categories (initiation (A), young (B), medium (C), mature (D) and old (E)) in the four forest types: Masson pine forest (a), Cunninghamia forest (b), hard broad-leaved forest (c) and soft broad-leaved forest (d). Mean and standard deviation of the estimated $T_{\text {NEP }}$ were calculated in the two periods of 1994-1998 and 1999-2003 from the eight provinces (region).

and the least in Masson pine forest $\left(41.2 \mathrm{~g} \mathrm{C} \mathrm{m}^{-2} \mathrm{a}^{-1}\right)$. The differences of $T_{\mathrm{NEP}}$ among the four forest types were significant in both periods of 1994-1998 $\left(P_{1994-1998}=0.04\right)$ and 1994-1998 $\left(P_{1999-2003}=0.03\right)$. Although $T_{\mathrm{NEP}}$ decreased clearly in the mature or old stage for all the four forest types, $T_{\mathrm{NEP}}$ in broad-leaved forests at the mature or old stage was still larger than the mean $T_{\mathrm{NEP}}$ during the five age stages in needle-leaved forests.

\subsection{Increment of carbon storage and rate of carbon sequestration in the future}

We assumed the area of each forest type in the period of 1999-2003 was the average level in 2000, which would not be disturbed and would be maintained in the study sites. Using the estimated parameters in the logistic regression functions in the period of 1999-2003, carbon storage in the four forest types was estimated from 2000 to 2050 (Table 4). The total carbon storage in aboveground biomass of trees in the four forest types started at $0.57 \mathrm{Pg} \mathrm{C}$ in 2000 and would reach $1.42 \mathrm{Pg} \mathrm{C}$ in 2050. The net carbon sequestration was $0.85 \mathrm{Pg} \mathrm{C}$ during this period, and the mean annual rate of increment was $4.27 \times 10^{-3} \mathrm{Pg} \mathrm{C} \mathrm{a}^{-1}$.

Of the four forest types, hard broad-leaved forest and Masson pine forest showed the largest mean annual rate of carbon sequestration from 2000 to 2050 (Table 4). In comparing the mean annual rate increment per unit area, both broad-leaved forests (hard and soft) showed greater carbon sequestration ability than the needle-leaved forest types (Table 4). We concluded the larger mean annual rate increment in Masson pine forest was driven by the larger forest area. However, the larger mean annual rate increment in hard broad-leaved forest was driven by the larger $T_{\mathrm{NEP}}$.

The above results indicate the four forest types will be important carbon sinks in the future in south China. However, their carbon sequestration rates will differ, with the largest potential in hard broad-leaved forest as it has both the large forest area and $T_{\mathrm{NEP}}$.

\section{Discussion}

\subsection{Reliability of logistic regression as a proxy for carbon sequestration prediction}

A number of studies on tree growth indicate plant biomass increases with forest stand age, and reaches an equilibrium or declines slightly in mature and old stages [15-17]. However, increasing amounts of soil organic carbon were found in many old-growth forests [3]. Old-growth forests have been considered to be carbon sinks worldwide [20,21]. Generally, biomass carbon accumulation rates increase continuously until the forest canopy closes; after that, it tends to decrease. Many studies reported these age-related patterns with logistic regression curves [15,17,22]. Using the data from the national forest inventory from 1994-1998 and 1999-2003, Figure 2 shows the relationship between $T_{\mathrm{ABC}}$ and forest stand age over time. A good trend of the logistic regression curve was also found in the present study.

The two logistic regression curves in each plot in Figure 2 were very similar, except for broad-leaved forests. At the mature or old stage, $T_{\mathrm{ABC}}$ for broad-leaved forests was larger in 1999-2003 than in 1994-1998, which was probably the result of positive impacts of human activates or 
Table 4 Predictions of aboveground biomass carbon storage and increment of carbon sequestration ability of tree layer for the four forest types from 2000 to $2050^{\text {a) }}$

\begin{tabular}{|c|c|c|c|c|c|c|c|c|c|}
\hline \multirow[b]{2}{*}{ Forest type } & \multirow{2}{*}{$\begin{array}{c}\text { Forest area in } \\
2000 \\
\left(\times 10^{9} \mathrm{~m}^{2}\right)\end{array}$} & \multicolumn{6}{|c|}{ Aboveground biomass carbon storage (Pg C) } & \multicolumn{2}{|c|}{ Increment of carbon sequestration ability } \\
\hline & & 2000 & 2010 & 2020 & 2030 & 2040 & 2050 & $\begin{array}{c}\text { Mean annual rate of } \\
\text { increment } \\
\left(10^{-3} \mathrm{Pg} \mathrm{C} \mathrm{a}^{-1}\right) \\
\end{array}$ & $\begin{array}{l}\text { Mean annual rate of } \\
\text { increment per unit area } \\
\left(\mathrm{g} \mathrm{C} \mathrm{m}^{-2} \mathrm{a}^{-1}\right)\end{array}$ \\
\hline Masson pine forest & 133.48 & 0.14 & 0.20 & 0.28 & 0.34 & 0.38 & 0.41 & 5.49 & 41.14 \\
\hline Cunninghamia forest & 118.46 & 0.10 & 0.16 & 0.22 & 0.26 & 0.28 & 0.29 & 3.73 & 31.53 \\
\hline $\begin{array}{l}\text { Hard broad-leaved } \\
\text { forest }\end{array}$ & 74.98 & 0.23 & 0.28 & 0.33 & 0.39 & 0.45 & 0.52 & 5.66 & 75.50 \\
\hline $\begin{array}{l}\text { Soft broad-leaved } \\
\text { forest }\end{array}$ & 28.79 & 0.10 & 0.13 & 0.15 & 0.18 & 0.20 & 0.21 & 2.18 & 75.68 \\
\hline Total carbon storage & & 0.57 & 0.77 & 0.98 & 1.16 & 1.31 & 1.42 & & \\
\hline
\end{tabular}

a) $1 \mathrm{Pg}=10^{15} \mathrm{~g}$.

environmental factors on forest carbon sequestration in the second period. However, comparing the parameters in the logistic regression curves derived from the same forest type in the two periods, no statistically significant $(P>0.05)$ difference was found between the two periods, and correlations in all four forest types were statistically significant $(P$ $<0.01)$ with $R^{2}>0.95$, which suggests the logistic regression curves could be used to predict $T_{\mathrm{ABC}}$ in our study.

\subsection{Carbon sequestration ability in the future in south China}

The two broad-leaved forest types studied are two major mixed forest types, while Pinus massoniana and Cunninghamia lanceolata forests are representative of pure coniferous forests in the tropical and subtropical regions of south China. $T_{\mathrm{ABC}}$ in these forests reflects the total forest carbon pools and their $T_{\mathrm{NEP}}$ determines the potential of forest carbon sinks in this study site.

$T_{\mathrm{ABC}}$ in broad-leaved forests is higher than in needle-leaved forests across five age categories, which indicates broad-leaved forests have larger aboveground biomass carbon pools per area. Also, the differences of $T_{\mathrm{ABC}}$ between broad-leaved and needle-leaved forests become larger as forest stand age increases. In south China, the areas of needle-leaved forests are much larger, influencing the magnitude of forest carbon sequestration in the future. This increase is also supported by the future carbon storage predicted by logistic regression. We concluded that all four forest types will be important carbon pools. $T_{\mathrm{NEP}}$ in all four forest types is above zero at each stage of the five age categories, which implies that trees in all forest types accumulate carbon in their biomass throughout their lifespan. $T_{\mathrm{NEP}}$ in broad-leaved forests is larger than $T_{\mathrm{NEP}}$ in needle-leaved forests, especially in the mature and old stages. The multi-layer canopy in broad-leaved forests may be one of the reasons causing these differences in $T_{\mathrm{NEP}}$. As tree biomass increases in a given forest stand, the competition for nutrients and water among trees intensifies leading to an increased mortality rate for dominant trees during forest suc- cession [23,24]. Gaps left by dead individuals allow a secondary canopy of trees to grow; this maintains the strong productivity of aboveground biomass $[21,25,26]$. There are usually two or three layers of tree canopy in mature or old broad-leaved forests. Although $T_{\mathrm{NEP}}$ in broad-leaved forests decreased significantly in mature and old stages as the canopy closed, it is still greater than $T_{\mathrm{NEP}}$ in needle-leaved forests. Therefore, we believe broad-leaved forests are better solutions for afforestation and reforestation in south China in light of their greater potential carbon accumulation ability compared with needle-leaved forests.

This work was supported by the Strategic Priority Research Program of Chinese Academy of Sciences (XDA05050205).

1 Dixon R K, Brown S, Houghton R A, et al. Carbon pools and flux of global forest ecosystems. Science, 1994, 263: 185-190

2 Beer C, Reichstein M, Tomelleri E, et al. Terrestrial gross carbon dioxide uptake: Global distribution and covariation with climate. Science, 2010, 329: 834-838

3 Zhou G Y, Liu S G, Li Z A, et al. Old-growth forests can accumulate carbon in soils. Science, 2006, 314: 1417

4 Pan Y D, Birdsey R A, Fang J Y, et al. A large and persistent carbon sink in the world's forests. Science, 2011, 333: 988-993

5 Tan Z H, Zhang Y P, Douglas S, et al. An old-growth subtropical Asian evergreen forest as a large carbon sink. Atmos Environ, 2011, 48: $1548-1554$

6 Yan J H, Wang Y P, Zhou G Y, et al. Estimates of soil respiration and net primary production of three forests at different succession stages in South China. Glob Change Biol, 2006, 12: 810-821

7 Piao S L, Fang J Y, Ciais P, et al. The carbon balance of terrestrial ecosystems in China. Nature, 2009, 458: 1009-1013

8 Chapin III F S, Matson P A, Mooney H A. Principles of Terrestrial Ecosystem Ecology. New York: Springer-Verlag New York, 2002. 285-287

9 Pregitzer K S, Euskirchen E S. Carbon cycling and storage in world forests: Biome patterns related to forest age. Glob Change Biol, 2004, 10: 2052-2077

10 Tuyl S V, Law B E, Turner D P, et al. Variability in net primary production and carbon storage in biomass across Oregon forests an assessment integrating data from forest inventories, intensive sites, and remote sensing. For Ecol Manage, 2005, 209: 273-291

11 Zhao M F, Xiang W H, Peng C H, et al. Simulating age-related changes in carbon storage and allocation in a Chinese fir plantation growing in southern China using the 3-PG model. For Ecol Manage, 2009, 257: 1520-1531 
12 The State Forestry Administration on Forest Resources Management Department. The major results of the sixth national forest resources inventory (in Chinese). 2006

13 The State Forestry Administration on Forest Resources Management Department. National forest resources continuous investigation technical regulations (in Chinese). 2003

14 Fang J Y, Chen A P, Peng C H, et al. Changes in forest biomass carbon storage in China between 1949 and 1998. Science, 2001, 292: 2320-2322

15 Law B E, Sun O J, Campbell J, et al. Changes in carbon storage and fluxes in a chronosequence of ponderosa pine. Glob Change Biol, 2003, 9: 510-524

16 Zaehle S, Sitch S, Prentice C, et al. The importance of age-related decline in forest NPP for modeling regional carbon balances. Ecol Appl, 2006, 16: 1555-1574

17 Hudiburg T, Law B, Turner D P, et al. Carbon dynamics of Oregon and Northern California forests and potential land-based carbon storage. Ecol Appl, 2009, 19: 163-180

18 Norby R J, Luo Y Q. Evaluating ecosystem responses to rising atmospheric $\mathrm{CO}_{2}$ and global warming in a multi-factor world. New Phytol, 2004, 162: 281-293
19 Luo Y Q. Terrestrial carbon-cycle feedback to climate warming. Annu Rev Ecol Evol Syst, 2007, 38: 683-712

20 Luyssaert S, Schulze E D, Borner A, et al. Old-growth forests as global carbon sinks. Nature, 2008, 455: 213-215

21 Zhang Y P, Tan Z H, Song Q H, et al. Respiration controls the unexpected seasonal pattern of carbon flux in an Asian tropical rain forest. Atmos Environ, 2010, 44: 3886-3893

22 Xu B, Guo Z D, Piao S L, et al. Biomass carbon stocks in China's forests between 2000 and 2050: A prediction based on forest biomass-age relationships. Sci China Life Sci, 2010, 53: 587-594

23 Ryan M G, Binkley D, Fownes J H. Age-related decline in forest productivity: Pattern and process. Adv Ecol Res, 1997, 27: 213-262

24 Delzon S, Loustau D. Age-related decline in stand water use: Sap flow and transpiration in a pine forest chronosequence. Agric For Meteorol, 2005, 129: 105-119

25 Tang X L, Wang Y P, Zhou G Y, et al. Different patterns of ecosystem carbon accumulation between a young and an old-growth subtropical forest in Southern China. Plant Ecol, 2011, 212: 1385-1395

26 Hardiman B S, Bohret G, Gough C M, et al. The role of canopy structural complexity in wood net primary production of a maturing northern deciduous forest. Ecology, 2011, 92: 1818-1827

Open Access This article is distributed under the terms of the Creative Commons Attribution License which permits any use, distribution, and reproduction in any medium, provided the original author(s) and source are credited. 